\title{
SCCmec and spa types of methicillin-resistant Staphylococcus aureus strains in Israel. Detection of SCCmec type V
}

\author{
I. Chmelnitsky • S. Navon-Venezia • A. Leavit • \\ E. Somekh • G. Regev-Yochay • M. Chowers • \\ P. Shitrit • Y. Carmeli
}

Published online: 15 March 2008

(C) Springer-Verlag 2008

Erratum to: Eur J Clin Microbiol Infect Dis (2007)

DOI 10.1007/s10096-007-0426-x

In the published original version of the article, the name of one co-author is misspelled. The correct name is given here:

G. Regev-Yochay

The authors apologize for this.

The online version of the original article can be found at http://dx.doi. org/10.1007/s10096-007-0426-x.

I. Chmelnitsky $\cdot$ S. Navon-Venezia $\cdot$ A. Leavit $\cdot$ Y. Carmeli

Division of Epidemiology and Laboratory for Molecular

Epidemiology and Antibiotic Research,

Tel Aviv Sourasky Medical Center,

Sackler Faculty of Medicine, Tel Aviv University,

Tel Aviv, Israel

E. Somekh

The Pediatric Infectious Diseases Unit, Wolfson Medical Center,

Holon, Sackler Faculty of Medicine, Tel Aviv University,

Tel Aviv, Israel

G. Regev-Yochay

The Infectious Diseases Unit, Sheba Medical Center, Ramat Gan,

Sackler Faculty of Medicine, Tel Aviv University,

Tel Aviv, Israel

M. Chowers · P. Shitrit

The Infectious Diseases Unit, Meir Medical Center,

Kfar Saba, Israel

I. Chmelnitsky $(\square)$

Division of Epidemiology, Tel Aviv Sourasky Medical Center,

6 Weizmann St,

Tel Aviv 64239, Israel

e-mail: innach@tasmc.health.gov.il 